\title{
Preparação metodológica dos professores para 0 trabalho de orientação profissional dos estudantes do curso de matemática do ISCED-Huambo
}

La preparación metodológica de los profesores para el trabajo de orientación profesional de los estudiantes de la carrera de Matemática del ISCED-Huambo

Teachers methodological preparation for professional or career guidance of students majoring in Mathematics at ISCED-Huambo

Odeth Chambula Cahete

ORCID: 0000-002-61 15-2230

Mestre. Assistente. Instituto Superior de Ciências de Educação do Huambo odethcahete@gmail.com

DATA DA RECEPÇÃO: Junho, 2020 | DATA DA ACEITAÇÃO: Janeiro, 2021

\section{RESUMO}

O presente artigo é parte da dissertação de mestrado, e teve como objectivo diagnosticar as insuficiências que professores do ISCED do Huambo apresentam para a realização do trabalho de orientação profissional desde o processo de ensino - aprendizagem e, a partir deste diagnóstico, elaborar acções metodológicas que contribuam para a preparação metodológica dos professores, para o trabalho de orientação profissional dos estudantes do primeiro ano do curso de Matemática do ISCED - Huambo. Na elaboração deste trabalho foram empregues métodos de investigação de nível teórico como: Histórico-lógico, análise-síntese, enfoque de sistema, indução-dedução; de nível empírico como: observação, análise documental, entrevista, questionário e por último o método estatísticomatemático. Os resultados do diagnóstico demonstram claramente as insuficiências que maior parte dos professores apresenta para realizar o trabalho de orientação profissional desde o processo de ensino aprendizagem.

Palavras-chave: orientação profissional; preparação metodológica; ISCEDHuambo. 


\section{RESUMEN}

El presente artículo es parte de la disertación de maestría e tuvo como objetivo diagnosticar las insuficiencias que los profesores del ISCED do Huambo presentan para la realización del trabajo de orientación profesional desde el proceso de enseñanza - aprendizaje y, a partir de este diagnóstico, elaborar acciones metodológicas que contribuyan a la preparación metodológica de los profesores, para el trabajo de orientación profesional de los estudiantes del primero año del curso de Matemática del ISCED Huambo. En la elaboración de este trabajo se utilizaron métodos de investigación de nivel teórico como: Histórico-lógico, análisis-síntesis, enfoque de sistema, inductivo - deductivo; de nivel empírico como: la observación, análisis documental, entrevista, cuestionario y por último el método estadístico-matemático. Los resultados del diagnóstico demuestran claramente las insuficiencias que mayor parte de los profesores presentan para la realización del trabajo de orientación profesional desde el proceso de enseñanza - aprendizaje.

Palavras clave: orientación profesional; preparación metodológica; ISCEDHuambo.

\section{ABSTRACT}

This article is part of a master's dissertation which aimed at finding out the shortcomings that ISCED teachers in Huambo presented in carrying out professional/career guidance tthrough the teaching-learning process and, based on the outcomesdevelop an action plan that will contribute to the methodological preparation of teachers, to the professional/career guidance of first year students majoring in Mathematics at ISCED - Huambo. This research made use of theoretical methods such as: Historical-logical, analysissynthesis, system approach, induction-deduction. Thus it also usedempirical methodssuch as: observation, document analysis, interview, and questionnaire. Lastly it also made use of statistical-mathematical methods. The results clearly demonstrate the insufficiencies that most teachers have to carry out professional/career guidance through the teaching - learning process.

Keywords: Professional Orientation; Methodologial Preparation; HuamboISCED. 


\section{INTRODUÇÃO}

A orientação profissional como um relacionamento de ajuda, por orientação psicológica ou educacional, não é uma relação de dependência em que o conselheiro diz ao orientado o que fazer e como fazê-lo. Mas sim, um espaço comunicativo através do qual o conselheiro cria as condições necessárias, isto é, situações de aprendizagem que propicie o desenvolvimento do potencial do orientado, para ele chegar sozinho a tomar decisões sobre sua vida profissional com a qual ele se sente comprometido, responsável e satisfeito (González, 2003).

Esta orientação profissional aqui enfatizada deve passar em primeiro lugar pelo nível de aspiração pessoal de cada estudante, as que por sua vez respondem a necessidades sociais. Por isso torna-se necessário questionar-se: como se desenvolve a orientação profissional desde os primeiros níveis de ensino? Quais são os interesses que prevalecem na hora de escolher uma futura profissão, os factores económicos, familiares ou os pessoais? Com que nível de conhecimentos acerca da futura profissão chegam os estudantes nos primeiros anos de formação e, como contribuem as instituições educativas superior na orientação profissional dos mesmos?

Todos estes questionamentos nos conduzem necessariamente a uma questão essencial que é a preparação metodológica de que deve dispor o professor para responder as exigências da orientação profissional na Universidade contemporânea e no contexto histórico em que se vive.

A autora desta investigação mediante a análise preliminar através da observação pôde constatar que maior parte dos professores do primeiro ano do curso de Matemática, do Instituto Superior de Ciências da Educação do Huambo (ISCED-Huambo) carecem de preparação metodológica para o trabalho de orientação profissional dos estudantes enquanto futuros profissionais. Constatou-se também que, os estudantes chegam ao curso sem dispor de alguma preferência pelo mesmo; não possuem atitudes profissionais pelo curso pedagógico e outros entraram no curso como uma maneira de obter um título universitário, mas não aspiram a exercer a profissão; outros ainda não dispõem antes de seu ingresso a educação superior de um curso pré-definido e, por isso, inscrevem-se em mais de um curso, na mesma ou em diferentes instituições de Ensino Superior.

A partir dessa ideia, requer-se preparar o professor para o trabalho de orientação profissional com vista a melhorar o ingresso e a permanência dos estudantes, já que não se pode pensar-se numa orientação profissional favorável para o estudante se não existir a intenção do colectivo de professores de que a própria qualidade da aula, a vinculação da teoria com 
a prática e, os próprios enfoques do currículo permitam desenvolver motivações profissionais nos estudantes.

\section{TEORIAS E ENFOQUES ACERCA DA ORIENTAÇÃO PROFISSIONAL}

Os estudos dos referentes teóricos sobre a orientação profissional conduzem esta investigação aos diferentes enfoques a partir dos quais se faz uma interpretação e análise dos factores que determinam tal processo. O estudo realizado por Gonzalez (2003, p.19), assinala que nestes enfoques que se vão construindo se reflectem as concepções dos autores acerca da motivação e sua expressão na actividade profissional.

A seguir sintetizam-se os diferentes enfoques e seus respectivos autores:

- Teorias factorialistas representadas por Parsons, Fingermann.

- As teorias psicodinámicas representadas por Bordin, Nachman, Holland.

- As teorias evolucionistas representadas por Super, Ginzberg.

As teorias factorialistas desenvolvidas por Parsnos \& Fingermann (1968, p. 26) assinalam como aspectos essenciais de sua teoria que a eleição profissional é considerada como um acto não determinado pelo sujeito, senão como resultado da correspondência entre as actitudes naturais do homem e as exigências da profissão, a qual é determinada pelos testes psicológicos.

- A orientação profissional nestas teorias limita-se ao descobrimento a partir dos testes daquelas características que possuem o sujeito e que podem facilitar ou obstacularizar seu futuro desempenho profissional. Estas teorias fundamentam-se na concepção factorialista da personalidade entendida como uma somatória de atitudes físicas, intelectuais, que se expressam directamente na conduta como características

Por sua vez, as teorias psicodinámicas representadas por Bordin, Nachman \& Holland s/d. citados por González( 2003, p.45), realizam suas contribuições às teorias da orientação profissional sobre um enfoque psicanalítico ao considerar a motivação profissional como a expressão de forças instintivas que se canalizam através do conteúdo de determinadas profissões. Segundo estas concepções a vocação é a expressão da sublimação de instintos reprimidos que tiveram sua manifestação na infância do sujeito e que encontra sua expressão socializadora na idade juvenil através da inclinação para determinadas profissões.

Ao referir-se sobre o carácter instintivo da vocação nestas teorias Cueli, (1973, p. 65), enfatiza o seguinte: "o facto de escolher uma ocupação como meio de vida implica uma repetição. A preferência basear-se-á inconscientemente na conduta que o sujeito viveu nas primeiras relações com o objecto de sua infância". 
Por outro lado, as teorias evolucionistas representadas por Super, Ginzberg \& Hará (1978, p. 45), concebem a vocação como uma expressão do desenvolvimento da pessoa. Atenção especial merece a concepção de Super (1968, p. 20), porque para este autor, a vocação é o resultado do desenvolvimento pessoal expressa no processo de eleição profissional. De acordo com o mesmo autor, opõe-se as teorias factorialistas e psicodinámicas ao criticar o carácter passivo que se atribui ao sujeito em sua participação no processo de eleição profissional. Pelo contrário, apesar das suas tentativas por explicar a eleição profissional como um resultado de nível de desenvolvimento alcançado pela personalidade e, neste sentido, destacar o papel activo do sujeito na eleição da profissão, não passa os marcos atomistas na concepção da motivação e da personalidade característico das teorias factorialistas ao relacionar a eleição da profissão com o desenvolvimento das características isoladas da personalidade.

As teorias factorialistas e psicodinámicas tiveram seu maior auge na primeira metade do século XX, enquanto as teorias evolucionistas se manifestaram com mais força a partir dos anos 50 (Idem). Isto se deve, fundamentalmente, ao desenvolvimento da Psicologia humanista, que marca novos pontos de vista e considerações acerca da orientação profissional ao destacar o papel protagónico do sujeito na eleição da profissão expressa no autoconhecimento e nas possibilidades de assumir responsavelmente sua decisão profissional.

A essência das teorias evolucionistas no reconhecimento da vocação como expressão do desenvolvimento da personalidade marca uma viragem nas práticas da orientação profissional. Estas deixam de ser vistas como acções isoladas da orientação profissional, que se realizam no momento determinado, no momento da eleição profissional e, a margem da escola, para se conceber como um processo de ajuda ao estudante que se realiza ao longo da sua vida escolar e inserido no processo de ensinoaprendizagem no que participa à qualidade do orientador não só o especialista (psicólogo) mas também todos os agentes educativos, professores, auxiliares pedagógicos e pais.

Nesta linha de pensamento acerca da evolução das teorias e enfoques sobre a orientação profissional notamos que por meio da influência da teoria evolucionista surge nos anos 70 nos Estados Unidos 0 movimento denominado educação para a carreira de Super \& Hall (1978, p.16). Por educação para a carreira se entende o conjunto de experiências orientadoras que se desenvolvem integradas no marco curricular da escola e que preparam para o curso a progressão vocacional de uma pessoa ao longo de sua vida. 
Santana et al. (1992, p. 56) diz que o movimento de educação para a carreira se produziu no contexto de uma Reforma Educativa que pretendia erradicar insuficiências detectadas no sistema do ensino norte-americano tais como:

- Inexistente relação entre a formação recebida e a exigida para exercer uma profissão.

- Falta de informação e preparação dos estudantes para enfrentar a transição escola trabalho.

- Falta de vinculação entre a instituição educativa e a comunidade.

Desta maneira, o movimento da educação para a carreira ao possibilitar a introdução da orientação profissional no currículo escolar e a vinculação da escola com a comunidade no trabalho de orientação profissional, permite ao estudante obter maior informação acerca de suas oportunidades laborais, ao mesmo tempo em que cria as condições no currículo escolar para a educação do autoconhecimento e autovaloração do estudante em relação as suas possibilidades para o estudo de uma profissão e para a tomada de decisões profissionais.

Uma análise detalhada sobre este enfoque permite descobrir suas potencialidades como se pode observar anteriormente, mas limita a orientação profissional que se realiza nas etapas prévias ao ingresso do estudante a um centro de formação profissional. Pelo que, o trabalho de orientação profissional neste enfoque, limita-se na preparação do sujeito para a eleição profissional.

Esta limitação observa-se na tentativa de desenvolver a orientação profissional dentro do currículo escolar, isto é, educação para a carreira toda a vez que as experiências neste sentido se realizam fundamentalmente nos níveis básicos e médios do ensino e muito poucas vezes na Educação Superior.

Outra limitação das teorias evolucionistas é a incompreensão da unidade dialéctica entre a natureza subjectiva, activa da personalidade e sua determinação histórico-social, o que impede entender que a construção da vocação por parte do estudante é um processo socialmente determinado, nas potencialidades da personalidade do estudante que the permite assumir uma eleição profissional responsável, são formadas no processo de interacção do estudante com o meio histórico-social no qual se desenvolve em virtude da qualidade das influências educativas que recebe.

Nenhuma das teorias vocacionais anteriormente referidas consegue explicar como se manifesta a unidade dialéctica dos factores internos e externos no processo da construção da vocação. 
As limitações que se apresentam na explicação da unidade dialéctica entre os factores internos e externos no processo da construção da vocação foram satisfeitos com o enfoque histórico-cultural do desenvolvimento humano que permite compreender como a personalidade tem ao mesmo tempo, uma natureza objectiva e subjectiva; tem ao mesmo tempo um carácter activo e autónomo na regulação da actuação e está determinada histórico e socialmente na sua origem e desenvolvimento.

Esta orientação profissional é concebida como parte do processo da educação da personalidade do sujeito que o prepara para a eleição, formação e actuação profissional responsável, no qual intervêm para a sua eficácia todos os agentes educativos da escola, da família e da comunidade que conjuntamente com os psicólogos e pedagogos conformam a equipe de orientadores profissionais.

\section{A AULA, ESPAÇO FUNDAMENTAL PARA O PROCESSO DE ORIENTAÇÃO PROFISSIONAL}

A aula enquanto uma das primeiras e fundamentais vias para o trabalho de orientação profissional é, acima de tudo, uma actividade pedagógicodidáctica fundamental por meio da qual o professor entra em contacto com o estudante e ao mesmo tempo, que diagnostica os seus problemas e potencialidades vinculadas à orientação profissional.

Além disso, Ganzález (2003, p.32), afirma que a aula serve de ponto de partida para o melhor conhecimento do estudante. Na aula realizam-se valorações sistemáticas e é o espaço mais quotidiano para receber influências e orientações para a profissão. Das boas aulas surgem muitas vivências e conhecimentos que mobilizam, primeiro o interesse cognoscitivo do estudante e depois seus interesses profissionais.

De tudo o que foi dito anteriormente, Savilombo (2018, p.9), sublinha que:

Independentemente da aula ser uma das primeiras e principais vias que o professor dispõe para realizar a orientação profissional dos estudantes, não pode ser qualquer aula e, de qualquer professor, mas sim, de um professor com preparação didácticopedagógica, que Ihe possibilite planificar, executar e controlar tal tarefa. Pelo que, a orientação profissional que aqui se advoga é intencional, sistematizada e não espontânea.

A sistematização das ideias dos autores acima referenciados faz com que a autora da presente investigação deduza que só o professor preparado para o trabalho de orientação profissional auxilia os estudantes na tomada de decisão profissional de um lado, do outro lado, só o professor preparado para esta missão saberá aproveitar as potencialidades que a aula the oferece para orientar profissionalmente os estudantes na direcção desejada. MATERIAL E MÉTODOS

Associação Multidisciplinar de Investigação Científica (AMIC)

Revista Angolana de Ciências. Publicação Arbitrada, Semestral. Vol. 3. No. 1. Ano 2021. (Janeiro - Junho) (1) $@(0$ 
Para a determinação do modelo da presente investigação, a autora do trabalho teve que considerar os critérios de classificação assumidos por Zayas \& Sierra (1998, p.42), que ao definirem as características deste modelo qualitativo, que é o modelo característico da presente investigação, destacam o facto de que nesse modelo, a teoria constitui uma reflexão da prática, tenta entender a realidade, descreve o facto do conhecimento a ser desenvolvido aprofundado em diferentes momentos da investigação.

A presente investigação adoptou o modelo qualitativo, porque é considerado como um processo activo, sistemático e rigoroso, pois o mesmo facilita conhecer o fenómeno tal como ocorre na realidade, oferecendo mecanismos para descrever, interpretar e explicar os factos em estudo. Nele, o investigador torna-se num agente activo do processo de mudança.

Do ponto de vista da sua tipologia, a presente investigação é descritiva pelo facto de permitir a descrição da realidade dos factos e as causas internas da situação actual sobre a preparação metodológica dos professores para o trabalho de orientação profissional e a apresentação da proposta para dar solução ao problema científico, cumprindo com o objectivo, perguntas e tarefas de investigação.

Nesta etapa da investigação para o diagnóstico do estado actual da preparação metodológica dos professores para o trabalho de orientação profissional dos estudantes do primeiro ano do curso de Matemática do ISCED-Huambo, trabalhou-se com directivos, professores e estudantes tal como se pode observar:

A população da presente investigação, esteve constituída por dez (10) professores que leccionam no primeiro ano do curso de Matemática do ISCED-Huambo, no ano lectivo de 2019 a 2020. Desta população trabalhouse com cem porcento da mesma, porque à luz dos livros de Metodologia de Investigação Científica de autores como: Bello (2005), Eco (2007), Alves (2012), Ramos \& Naranjo (2014), quando a população não for vasta, não é obrigatório extrair-se uma amostra.

Por outro lado, além de trabalhar com os professores que constituem a população do presente trabalho, trabalhou-se igualmente com três (3) membros do corpo directivo e vinte e quatro (24) estudantes do primeiro ano do curso de Matemática regular do ISCED-Huambo, considerados como fonte de informação. 
A ANÁLISE DO PLANO CURRICULAR DO CURSO DE MATEMÁTICA E ALGUNS PROGRAMAS DAS DISCIPLINAS DO PRIMEIRO ANO CURSO DE MATEMÁTICA ISCED-HUAMBO

O regulamento do trabalho docente metodológico do Ensino Superior cubano, no seu Artigo 14\%, enfatiza que o plano de estudos é o documento fundamental de carácter estatal que estabelece a direcção geral e o conteúdo principal da preparação profissional. É preparado para cada curso em correspondência com as necessidades existentes no país, os avanços científicos e tecnológicos da era actual e as particularidades da profissão em questão.

Desde esta lógica, o plano curricular do primeiro ano do curso de Matemática do ISCED-Huambo foi analisado com o objectivo de perceber os elementos essenciais que regulam a formação desse profissional. Por outro lado, o mesmo plano de estudo analisado revelou-se propício e necessário para a formação de profissionais de alto nível, capazes de desenvolver actividades pedagógicas no campo da Matemática.

No caso dos programas das disciplinas do primeiro ano, três programas foram seleccionados dentre as dez (10) disciplinas ministradas neste ano acadêmico tais como: Álgebra Linear, Análise Matemática I e Geometria Analítica. No caso dos três programas, limitam-se apenas à definição dos objectivos do programa e do sistema de conhecimentos, além de não serem definidas as habilidades cognitivas e genéricas que o estudante deve desenvolver após a conclusão do curso.

É sugestão da autora da presente pesquisa que o plano curricular do curso não considera os problemas profissionais que esses estudantes devem resolver após a graduação, nem se refere às habilidades que, do ponto de vista cognitivo, processual e atitudinal, o estudante deve desenvolver.

\section{A ENTREVISTA APLICADO AO CORPO DIRECTIVO}

O objectivo do guia de entrevista foi de conhecer as principais formas utilizadas pela direcção da instituição para desenvolver a preparação metodológica dos professores para o trabalho de orientação profissional dos estudantes do primeiro ano do curso de Matemática regular do ISCED Huambo.

A mesma entrevista foi realizada com três (3) membros do corpo directivo nomeadamente o Director Geral, Director Geral Adjunto para área científica e o Director Geral adjunto para área académica, que serviram como uma fonte de informação para esta pesquisa. Para tal, a questão número um (1) foi encaminhada ao conhecimento de quais elementos são considerados no 
planeamento da preparação metodológica dos professores, cujos resultados revelaram que $100 \%$ do corpo directivo concordam que o conhecimento académico dos professores na base da sua experiência deve ser considerado. Ainda acrescentam como elemento significativo para a preparação metodológica o conhecimento disponível para os professores sobre o plano de estudos e as demandas da própria universidade.

A pergunta número dois (2), que procurava saber dos directivos as principais limitações da preparação metodológica dos professores para desenvolver a orientação profissional dos estudantes do curso de Matemática, os directivos expressaram o seguinte: "a principal limitação demanda da falta de actividades promovidas pela instituição ligadas à orientação profissional; falta de encontro metodológico onde se abordam temas ligados ao assunto em destaque".

Já a pergunta número (3) três que pedia aos directivos para que dissessem as possíveis formas a utilizar para a preparação metodológica dos professores para desenvolver a orientação profissional dos estudantes do curso de Matemática, as propostas dos directivos recaíram nos seguintes aspectos: "incentivar os círculos de interesses no processo de ensino e aprendizagem da Matemática, com olimpíadas periódicas, para os professores mais e maior dedicação aos regentes da disciplina; seminários, conferências, introdução da cadeira de orientação profissional no plano de estudo do ISCED-Huambo em todos os cursos; realização de palestras e seminários de capacitação, realização de encontros metodológicos onde se discuta sobre o tema".

A pergunta número (4) quatro que procurava saber dos directivos os elementos a partir dos quais se determinam os conteúdos da preparação metodológica dos professores para desenvolver a orientação profissional dos estudantes do curso de Matemática, os directivos dizem o seguinte: "didácticas e científicas; pelos objectivos pretendidos, questões práticas do dia-a-dia onde seja notório o emprego da Matemática na vida; o objectivo é o elemento fundamental para traçar as demais acções uma vez que este representa o componente reitor onde deriva todo o processo de ensino e aprendizagem".

Quanto a número cinco (5) que procurava saber dos directivos se o desenvolvimento de actividades metodológicas pode contribuir para a preparação metodológica dos professores para desenvolver a orientação profissional nos estudantes do curso de Matemática, os resultados indicam que os directivos são unânimes, tal como se pode observar na tabela abaixo. 
Tabela 1: Representação das actividades metodológicas para a preparação dos professores

\begin{tabular}{|c|ccc|}
\hline Pergunta & Categorias & FA & \% \\
\hline \multirow{2}{*}{5} & Sim & 3 & 100 \\
\cline { 2 - 4 } Total & Não & 0 & 0 \\
\cline { 2 - 4 } & & 3 & 100 \\
\hline
\end{tabular}

Fonte: autora

Quando se pediu aos directivos que fundamentassem suas respostas, os resultados revelaram o seguinte: " quanto melhor for a metodologia do professor, maior será a motivação do sujeito que aprende; é a via de estimular o exercício de promoção da actividade de orientação profissional; as actividades metodológicas permitem a criação de condições necessárias para a prossecução de todo o processo uma vez que com estas actividades os professores estarão capacitados para orientarem melhor os seus estudantes.

QUESTIONÁRIO, APLICADO AOS PROFESSORES QUE LECCIONAM NO PRIMEIRO ANO DO CURSO DE MATEMÁTICA REGULAR

O questionário de seis (6) perguntas foi aplicado a dez (10) professores que leccionam no primeiro ano do curso de Matemática regular que, por sua vez, constituem a população desta pesquisa, com o objectivo de diagnosticar o estado actual da preparação metodológica dos professores para desenvolver a orientação profissional dos estudantes do primeiro ano do curso de Matemática do ISCED - Huambo.

A pergunta número um (1) que procurava saber se os professores já ouviram falar de orientação profissional, os resultados revelaram que os professores são unânimes ao afirmarem que sim já tinham ouvido falar sobre a orientação profissional tal como se pode observar na tabela abaixo.

Tabela 2: Orientação profissional

\begin{tabular}{|l|cccc|}
\hline \multicolumn{1}{|c|}{ Pergunta } & Categorias & FA & \% \\
\hline \hline 1 & & Sim & 10 & 100 \\
\cline { 3 - 5 } & & Não & 0 & 0 \\
\cline { 3 - 5 } & \multirow{3}{*}{ Total } & & 10 & 100 \\
\hline
\end{tabular}

Fonte: autora

E na mesma pergunta quando os professores foram questionados sobre o que era a orientação profissional, foi possível obter-se as seguintes respostas: 
"é o processo de conduzir profissionalmente alguém"; "é orientar o estudante em sua vida profissional"; "auxilia o jovem estudante para escolher a sua futura profissão"; "é o processo que visa capacitar o estudante de forma sólida para realizar de forma eficiente a sua profissão".

Por outro lado, "é a orientação ou formação integral e multifacética"; "via pela qual se orientam mediante diferentes actividades os estudantes a escolher sua futura profissão, melhor curso para sua formação"; " é um processo que permite facilitar um indivíduo na escolha de uma profissão"; " é a preparação antecipada da formação profissional que se deseja seguir"; "é o processo pelo qual os estudantes são orientados na escolha de uma profissão de acordo com as suas habilidades e aptidões".

As ideias expressas pelos professores revelam que, hoje mais do que nunca, os serviços de orientação profissional precisam ser fomentados pelas instituições educativas, sobretudo as de perfil pedagógico, a fim de se auxiliar os estudantes que se encontram em formação. Daí que Kapitiya, (2014, p. 56) foi claro ao enfatizar, a falta de orientação e oportunidade provocou profissionais deslocados. E as consequências são bem notórias: diploma na mão, mas sem competência profissional. Hoje, são eles os educadores sociais, os professores dos nossos filhos, são técnicos médios de saúde cuidando da nossa saúde. São secretários/secretárias e não sabem redigir uma carta oficial, um mini- relatório, uma certidão, Para aliviar o chefe, em todos os sectores, são eternos estagiários.

A pergunta dois (2) tencionava saber dos professores, que importância atribuem à orientação profissional, os resultados revelaram o seguinte: "facilitar o conhecimento para a escolha profissional"; "facilitar no autoconhecimento para uma escolha inteligente da futura formação"; "ajuda na escolha do curso ou opção de formação"; " tem importância para desenvolver o capital humano"; "muito importante na medida em que permite que o profissional escolha a sua profissão tendo em conta à sua vocação". E alguns professores não responderam a pergunta.

Quanto à pergunta três (3) que questionava os professores, quando se deve desenvolver a orientação profissional dos estudantes, os resultados revelaram que, alguns dizem "desde o primeiro ciclo", "no primeiro ano"; "quando for necessário"; "no teste de admissão", ao passo que outros não sabem quando se deve desenvolver a orientação profissional dos estudantes.

Quanto à pergunta quatro (4) que buscava saber dos professores se consideravam preparados didáctica e metodologicamente para desenvolver a orientação profissional durante o processo de ensino- 
aprendizagem, os resultados tal como se pode observar na tabela abaixo indicam que maior parte dos professores se considera preparado para 0 efeito.

Tabela 3: Preparação didáctica e metodológica dos professores

\begin{tabular}{|c|ccc|}
\hline Pergunta & Categorias & FA & \% \\
\hline \multirow{2}{*}{4} & Sim & 8 & 80 \\
\cline { 2 - 4 } Total & Não & 2 & 40 \\
\cline { 2 - 4 } & & 10 & 100 \\
\hline
\end{tabular}

Fonte: autora

A pergunta número cinco (5) que procurava saber dos professores se já participaram em alguma preparação metodológica para desenvolver a orientação profissional dos estudantes, maior parte dos professores diz que não. Esta resposta dos professores contradiz a resposta dada pelos mesmos na quarta pergunta e, por outro lado, revela a necessidade que os mesmos têm em aprender como realizar a orientação profissional dos estudantes.

Esta necessidade que os professores têm em relação ao trabalho de orientação profissional dos estudantes, coincide com os dizeres de Savilombo (2018,p.6), quando enfatizava que, apesar da aula ser o espaço ideal para a orientação profissional dos estudantes, esta não pode ser qualquer e, tão pouco de qualquer professor; mas sim, a de um professor que tenha uma preparação adequada para esta missão.

Tabela 4: Preparação metodológica dos professores para desenvolverem a Orientação profissional

\begin{tabular}{c|ccc|}
\hline \hline Pergunta & Categorias & FA & \% \\
\hline \hline 5 & Sim & 3 & 30 \\
\cline { 2 - 4 } Total & Não & 7 & 70 \\
\hline \hline
\end{tabular}

Fonte: autora

Quanto à pergunta seis (6) que tinha a intenção de explorar se os professores durantes as aulas têm realizado actividades que visam desenvolver o processo de orientação profissional dos estudantes, os resultados revelam que maior parte não tem realizado este processo.

Outro elemento interessante é de que, mesmo os professores que afirmaram que durante as aulas realizam actividades que visam desenvolver o processo de orientação profissional, um dos três, não soube citar duas actividades que tem realizado, ao passo que, os outros dois, primeiro não conseguiram citar 
as duas actividades e segundo as próprias actividades propostas por eles nada tem a ver com o trabalho de orientação profissional.

Tabela 5: Actividade que visam desenvolver o processo de orientação profissional.

\begin{tabular}{|c|ccc|}
\hline Pergunta & Categorias & FA & $\%$ \\
\hline 6 & Sim & 3 & 30 \\
& Não & 7 & 70 \\
\hline Total & & 10 & 100 \\
\hline
\end{tabular}

Fonte: autora

Em resumo, o questionário aplicado aos professores verificou as insuficiências e deficiências que os professores do primeiro ano do curso de Matemática regular têm para desenvolver o processo de orientação profissional dos estudantes, determinou-se do outro lado que, do ponto de vista cognitivo, os professores são identificados com o processo, mas não desenvolvem actividades durante as aulas que despertem o interesse dos estudantes para a profissão, mais uma vez foi demonstrada a necessidade de desenvolver acções metodológicas para preparar os professores com procedimentos, vias e métodos que permitam contribuir para esse processo.

Desta, pode-se perceber a preocupação e a necessidade que o corpo directivo atribui a temática. Outros, sim reconhecem que a escolha profissional torna-se um momento complexo na vida de um estudante. Ao optar por uma carreira, o mesmo busca conciliar sua idealização pessoal com o que está sendo oferecido pelo mercado de trabalho e o transmitido pelo professor concretamente na sala de aula. Caso ocorra de forma negativa as expectativas acima referida, pode provocar Por exemplo, a desmotivação na continuidade do curso ou se terminar, poderá não estar motivado e capacitado em resolver os problemas da profissão.

\section{QUESTIONÁRIO APLICADO AOS ESTUDANTES DO $1^{\circ}$ ANO DO CURSO DE MATEMÁTICA REGULAR}

O questionário aplicado aos estudantes teve como objectivo diagnosticar o estado actual do processo de orientação profissional dos estudantes do primeiro ano do curso de Matemática do ISCED-Huambo. A pesquisa aplicase a 24 estudantes que constituem uma fonte de informação. A idade dos mesmos, variam entre 17 a 28 anos de idade com maior representatividade o sexo Masculino.

A pergunta número um (1) que explorava os estudantes, se as primeiras orientações sobre o curso de Matemática do qual estão a frequentar as 
receberam da família, da escola, dos amigos ou outros, as respostas dos mesmos revelam que, os estudantes tal como se pode observar na tabela abaixo tiveram as primeiras orientações para o curso de Matemática de diferentes agências e agentes educativas.

Tabela 6: As primeiras orientações sobre o curso de Matemática

\begin{tabular}{|c|ccc|}
\hline Pergunta & Categorias & FA & \% \\
\hline \multirow{3}{*}{1} & Família & 6 & 25 \\
& A escolar & 9 & 37.5 \\
\cline { 2 - 4 } & Amigos & 5 & 20.83 \\
\cline { 2 - 4 } & Outros & 4 & 16.6 \\
\hline Total & & 24 & 100 \\
\hline
\end{tabular}

Fonte: autora

Este resultado revela que, sempre que alguém estiver no processo de escolha profissional, deve ser ajudado pelas agências e agentes educativos, como é o caso da família, professores, entre outros, pois, as consequências desta decisão podem afectar a todos. Por isso Soares, $(2002$, p.15) enfatizava dizendo:

Embora a escolha profissional seja responsabilidade de cada um, as consequências da decisão têm inúmeras implicações sociais. Uma pessoa que exerce sua profissão com motivação está não só se realizando como também prestando um serviço de melhor qualidade a sociedade.

Os estudantes que fazem referência à família, justifica-se pelo facto de a família ser núcleo onde os indivíduos são formados desde pequenos e onde também adquirem uma série de valores que os faz perceber as coisas de maneira muito particular.

Por outro lado, os amigos aparecem com outra percentagem porque como diz Soares (1993, p.13 -14) o trabalho em grupo tem alcançado melhores resultados na prática profissional por vários motivos:

- É próprio do adolescente e do jovem o convívio em grupos e turmas. É importante, no momento em que ele está buscando a sua identidade, sentir-se igual aos outros. Para poder se diferenciar no seu grupo familiar, ele precisa sentir-se pertencente a outro grupo;

- Há possibilidade de compartilhar sentimentos de dúvida, confusão e insegurança em relação à escolha profissional e ao seu futuro;

- Cada participante do grupo é um facilitador, pois a sua possibilidade de entender o outro e poder expressar como o percebe, auxiliam no conhecimento que cada membro busca de si mesmo. 
Ainda na primeira pergunta, quando os estudantes foram questionados sobre quais foram às orientações recebidas das agências e agentes educativos, as respostas divergiram, tal como se observa: "vantagem sobre o curso de Matemática"; "empenhar-se nos estudos e nunca desistir"; " seguir o curso de Matemática pelo facto de eu ter o potencial"; "a Matemática é um bom curso"; "notaram que amo ensinar e entendo Matemática"; "Por eu ter feito no ensino médio Matemática e Física"; "prestar muita atenção nos números e fórmulas"; " o gosto de ensinar a disciplina de Matemática"; " disseram-me que tinha vocação pela Matemática".

A pergunta dois (2) que procurava saber as razões que terão levado os estudantes a escolherem o curso de Matemática, os resultados indicam o seguinte: "facilidade de aprender e o gosto pela Matemática"; " por inclinação"; influência de professores e amigos"; " amor pela Matemática e a arte de ensinar"; ser professor de Matemática"; o gosto pelos cálculos geométrico e equações" e outros não responderam.

A partir desses pressupostos, torna-se necessário corroborar com Savilombo (2018, p.5) quando diz que, o professor na sua actuação profissional deve aproveitar a aula, para realizar a orientação profissional dos estudantes, a fim de estimular nos estudantes o interesse pelo curso e a permanência no mesmo com motivação e satisfação. Mas, o professor só o fará se tiver a preparação necessária para realizar este papel.

Quanto à pergunta três (3) que pedia aos estudantes para que, das alternativas apresentadas tal como se observa na tabela abaixo, seleccionassem uma, os resultados revelam que maior parte seleccionou o gosto pela profissão de professor.

Tabela 7: O momento da escolha do curso de Matemática

\begin{tabular}{|c|c|c|c|}
\hline Pergunta & Categorias & FA & $\%$ \\
\hline \multirow[t]{5}{*}{3} & $\begin{array}{l}\text { O gosto pela profissão de } \\
\text { professor }\end{array}$ & 15 & 62.5 \\
\hline & Influência da familia & 2 & 8.3 \\
\hline & Não tinha outra opção & 3 & 12.5 \\
\hline & $\begin{array}{l}\text { Tinha informações prévias } \\
\text { sobre o curso }\end{array}$ & 3 & 12.5 \\
\hline & Questões esconómicas & 1 & 4.16 \\
\hline Total & & 24 & 100 \\
\hline
\end{tabular}


Fonte: autora

Este resultado exige que no curso de Matemática exista professores preparados para poderem leccionar a Matemática tal como convém, a fim de, serem modelos vivos para os seus estudantes.

Por isso, Savilombo (2018, p.9) foi claro ao enfatizar numa das potencialidades que a aula oferece para a orientação profissional dos estudantes, quando dizia que a aula: "permite potenciar os interesses e motivações profissionais". E, continua dizendo: "se o desempenho profissional do professor é correcto didacticamente, resulta então atractivo e significativo para os estudantes e, desta maneira se pode estimular a vocação para o curso de sua eleição".

Já a pergunta quatro (4) que explorava se os estudantes gostavam do curso de Matemática, os resultados revelam que os estudantes são unânimes ao afirmarem que, sim, gostam. Para a autora desta investigação, esta resposta constitui uma potencialidade para este curso, pelo que, é preciso trabalhar com os estudantes quanto ao assunto de orientação profissional, de maneira que este desejo de não mudar de curso continue e que pouco e pouco desenvolvam capacidades e habilidades requeridas para um formado em Matemática em Ciências da Educação.

Tabela 8: Gosto pelo curso de Matemática

\begin{tabular}{|c||c|c||c|}
\hline Pergunta & Categorias & FA & \% \\
\hline \multirow{3}{*}{4} & Sim & 24 & 100 \\
\cline { 2 - 4 } Total & Não & 0 & 0 \\
\cline { 2 - 4 } & & 24 & 100 \\
\hline
\end{tabular}

Fonte: autora

A pergunta número cinco (5) que explorava se os estudantes reconhecem que as disciplinas que recebem no primeiro ano Ihes oferecem ferramentas para o seu futuro como profissionais, as respostas dos mesmos são unânimes, tal como se pode observar na tabela abaixo. Este resultado revela que os estudantes recebem das disciplinas ferramentas propícias para se obter resultados satisfatórios no curso de Matemática.

Tabela 9: Reconhecimento das disciplinas recebidas durante $01^{\circ}$ Ano

\begin{tabular}{|c|c|c|c|}
\hline Pergunta & Categorias & FA & \% \\
\hline \multirow{3}{*}{5} & Sim & 24 & 100 \\
\cline { 2 - 4 } Total & Não & 0 & 0 \\
\cline { 2 - 4 } & & 24 & 100 \\
\hline
\end{tabular}


Fonte: autora

Quanto à pergunta seis (6) que pedia aos estudantes para que dizerem como deve ser um futuro profissional de Matemática, os resultados revelam o seguinte: "conhecedor dos princípios didácticos"; " deve ser um excelente profissional"; " deve ser munido de conhecimentos matemáticos"; "ser bom para transmitir o seu saber às novas gerações"; " deve buscar mais e mais conhecimentos"; "deve ter domínio da Matemática e amor pela profissão".

Por outro lado, outros afirmam: "aquele que é preparado profissionalmente e matematicamente"; "deve ter capacidade de instruir e educar"; " deve gostar da profissão e da ciência"; " deve possuir bases de Matemática, deve ser humilde e ter boas técnicas de como ensinar a Matemática". Daí que a responsabilidade de estimular nos estudantes estes pressupostos anteriormente evocados, recai aos professores do curso de Matemática.

\section{TRIANGULAÇÃO DOS RESULTADOS}

Os resultados da triangulação de fontes nos apresentam as seguintes regularidades:

A Lei de Bases do Sistema Educativo angolano, Lei no 17/16: embora o desenvolvimento do processo de orientação profissional não seja explicitamente definido, ele aparece de maneira intrínseca, uma vez que, como Lei, estabelece as bases para o desenvolvimento de outras reformas particulares desenvolvidas a partir das características de cada subsistema de ensino, mas a essência da educação como processo social está incorporada, quando se afirma: formar um indivíduo treinado e preparado para se inserir na sociedade e contribuir para o desenvolvimento dela.

O plano de estudos do curso de Matemática e os programas de disciplinas consultados evidenciaram carências do ponto de vista metodológico, que não fornece aos professores ferramentas para desenvolver o processo de orientação profissional, limitando-se ao sistema de conhecimento e aos objectivos estabelecidos de maneira muito geral além de não serem definidas as habilidades cognitivas e genéricas que o estudante deve ter após a conclusão do curso.

O questionário aplicado aos professores permitiu revelar insuficiências e deficiências do ponto de vista cognitivo. Os professores estão identificados com o processo de orientação profissional, mas não desenvolvem actividades durante as aulas que despertam o interesse dos estudantes para a profissão. Tudo isto demonstra a necessidade de desenvolver acções metodológicas para favorecer os professores de procedimentos, vias e métodos que os permita contribuir para esse processo. 
O questionário aplicado aos estudantes permitiu constatar que o nível de orientação profissional com que os estudantes chegam ao Ensino Superior não é suficiente e que essas orientações chegaram a eles por diferentes agentes socializadores (família, amigos, escola). Sua preferência pelo curso é determinada pelas atitudes e habilidades em relação à matemática, que não constitui uma generalidade, porque nem todos os estudantes percebem como cada uma das disciplinas contribui para sua futura profissão, o que demonstra que o trabalho de orientação profissional deve ser uma prioridade do colectivo de professores.

Tudo isso demonstra a necessidade de desenvolver acções metodológicas que contribuam para a preparação metodológica dos professores do primeiro ano do curso de Matemática regular do ISCED-Huambo para o trabalho de orientação profissional dos estudantes.

PROPOSTA DE ACÇÕES METODOLÓGICAS

Pretende-se com esta proposta desenvolver acções metodológicas que contribuam para a preparação dos professores para o desenvolvimento do processo de orientação profissional a partir das dimensões académicas, de pesquisa e práticas do processo.

ACÇÃO METODOLÓGICA N 1: A orientação profissional: Um desafio para o professor universitário.

Objectivo: Explicar os elementos essenciais do processo de orientação profissional e suas características no Ensino Superior.

Forma de organização: Reunião metodológica.

Participantes: Professores.

Duração: 45 minutos.

Método: Elaboração conjunta.

Meios: Computador, ponteiro, marcadores de cor, folhas A4 ou outro tipo de papel, lapiseiras e retroprojector.

Orientações metodológicas: nesta primeira acção metodológica, ministra-se uma conferência introdutória sobre elementos gerais da orientação profissional, sua definição, características, etapas e sua essência no ensino universitário, uma vez que, no diagnóstico ter-se-á evidenciado de que alguns professores apresentam dificuldades nesse processo.

O profissional seleccionado para proferir esta conferência deve ser uma pessoa com experiência no trabalho didáctico e metodológico e com maior categoria académica e científica. A reunião metodológica tem dois 
momentos, na primeira etapa o conferencista deve trabalhar os aspectos didácticos metodológicos sobre os componentes do processo de ensino aprendizagem. Nesta mesma ordem considera-se as especificidades didácticas deste processo no Ensino Superior. O segundo momento será a avaliação. Pedir para que cada professor expresse numa só palavra como foi o encontro, e deve fundamentar sua posição.

ACÇÃO METODOLÓGICA N²: como promover a orientação profissional para o curso de Matemática desde a sala de aulas.

Objectivo: Instruir os professores sobre como se deve tratar a orientação profissional a partir dos conteúdos do curso de Matemática na da sala de aulas.

Forma de organização: Aula metodológica instrutiva.

Participantes: Professores.

Duração: 45 minutos.

Método: Elaboração conjunta.

Meios: Computador, ponteiro, marcadores de cor, folhas A4 ou outro tipo de papel, lapiseiras e retroprojector.

Orientações metodológicas: esta é a segunda acção metodológica a ser desenvolvida. A mesma teve como ponto de partida, o primeiro encontro metodológico que esteve centrado nas referências teóricas sobre o desenvolvimento da orientação profissional. Na presente actividade, a partir das contribuições de González (2003) e Savilombo (2018), procederá à análise do potencial que a aula oferece para desenvolver a orientação profissional.

O professor com mais experiência e categoria expõe, por meio de uma apresentação em power point, os elementos teóricos sobre o assunto, passando a exemplificar um tipo de actividade a ser desenvolvida na sala de aulas a partir de uma disciplina do currículo do primeiro ano do curso de Matemática.

Em seguida, prossegue formando três equipas de trabalho distribuídas igualmente, cada equipa trabalhará com um tema já abordado na exposição e depois seleccionará um membro da equipa que, a partir das experiências de todos, realizará uma intervenção em plenária.

É válido considerar o seguinte:

- O trabalho em equipa permite o diálogo directo com os estudantes em função de sua futura ou (vigente) profissão. 
- Permite conhecer e transmitir experiências para desenvolver interesses profissionais nos estudantes;

- Facilita explorar as possibilidades dos conteúdos em função da orientação profissional;

- Permite orientar tarefas e actividades para pôr o estudante em contacto com a sua futura profissão (por exemplo, a visita dos estudantes a uma escola, possibilita-lhes estar em contacto com sua realidade actual e futura);

- Permite potenciar os interesses profissionais (se o desempenho profissional do professor for correcto didacticamente, resulta então atractivo e significativo para os estudantes e, desta maneira, pode-se estimular a vocação para o curso de sua eleição).

Avaliação: pedir para que cada professor seleccione uma das palavras abaixo como: $O$ encontro foi interessante, produtivo e fundamenta sua resposta.

ACÇÃO METODOLÓGICA N³: "Festival das matemáticas".

Objectivo: demonstrar aos professores do primeiro ano do curso de Matemática regular do ISCED-Huambo como desenvolver habilidades profissionais em Matemática na sala de aulas.

Forma de organização: Aula demonstrativa.

Participantes: Professores e estudantes.

Duração: 45 minutos.

Método: Elaboração conjunta.

Meios: Computador, ponteiro, marcadores de cor, folhas A4 ou outro tipo de papel, lapiseiras e retroprojector.

Orientações metodológicas: esta parte inicial o professor aborda em primeiro lugar o estado actual em que o assunto deve ser tratado e insiste na necessidade de trabalhar em uma actualização e preparação metodológica para desenvolver o processo de orientação profissional e, especificamente, o treinamento de habilidades e interesses para a profissão pedagógica na especialidade de Matemática. Também deve considerar os elementos abordados nas primeiras acções metodológicas.

Posteriormente é seleccionada a disciplina de Didáctica localizada no segundo semestre do primeiro ano do curso. É feita uma chamada para o festival de matemática, onde as equipas previamente compostas por oito alunos (4 equipas) são formadas. Cada equipa deve apresentar uma proposta sobre como desenvolver uma aula de Matemática, definir previamente os indicadores pelos quais devem orientar a apresentação ou 
proposta, além de levar em consideração o conteúdo abordado na disciplina em questão.

Os indicadores definidos são os seguintes:

- Definição correcta dos objectivos, conteúdos, métodos, meios e avaliação em sala de aulas e estabelecimentos das relações entre eles.

- Criactividade nas actividades propostas.

- Uso de recursos didácticos.

Avaliação: cada equipa de trabalho realiza sua dissertação e um júri integrado pelos professores do primeiro ano e especialista em Matemática decide qual é a equipa vencedora.

ACÇÃO METODOLÓGICA No 4: O professor de Matemática que todos queremos (ser ou ter?)

Objectivo: reflectir sobre as características que o professor de matemática deve ter

Forma de organização: seminário metodológico.

Participantes: Professores.

Duração: 45 minutos.

Método: Elaboração conjunta.

Meios: Computador, ponteiro, marcadores de cor, folhas A4 ou outro tipo de papel, lapiseiras, retroprojector.

Orientações metodológicas: características do seminário: a técnica da sessão propõe um espaço e um tempo de comunicação, reflexão e criatividade participativa, onde o importante é o processo e não o produto terminado. A sessão é protagónica, activa e vivencial, mobilizando aos participantes a compartilhar e colaborar. Para o seu desenvolvimento é importante criar um clima de abertura e de confiança recíproca e de aceitação de cada um e o respeito mútuo, promovendo a participação de todos.

Temas fundamentais para trabalhar:

- O dever de ser professor de Matemática.

- O professor de Matemática que gostaria de ser.

- Sou docente, e sou professora de Matemática. Indicações metodológicas:

De forma antecipada, os professores conhecerão as temáticas e os objectivos que se propõem para sua realização em equipas de três ou de 
quatro pessoas. Os critérios para o efeito podem ser relações pessoais ou qualquer outro que se considerem pelos participantes.

Para um tratamento teórico e metodológico sobre o tema, deve-se fazer uso da bibliografia seleccionada e contribuir para a experiência de como é realizado o processo na realidade com base nestes dois elementos devem projectar as vias para aperfeiçoar este processo.

A sessão contará com a participação dos professores do primeiro ano do curso de Matemática.

Avaliação: os participantes têm dez minutos para a defesa dos seus trabalhos e deverão apresentar os seus trabalhos em diapositivos de power point, esquemas lógicos e os elementos que identifiquem a temática seleccionada. Avalia-se a criatividade dos professores, os meios e os métodos empregues para dar a conhecer aqueles aspectos nos quais trabalhem. O processo avaliativo também implicará o desenvolvimento das habilidades cognitivas e inquiridoras para trabalhar o tema.

\section{ACÇÃO METODOLÓGICA N5}

Objectivo: socializar os resultados obtidos durante o desenvolvimento das acções metodológicas para o desenvolvimento do processo de orientação profissional.

Forma de organização: Seminário integrador.

Participantes: Professores.

Duração: 45 minutos.

Método: Elaboração conjunta.

Meios: Computador, ponteiro, marcadores de cor, folhas A4 ou outro tipo de papel, lapiseiras e retroprojector.

Orientações metodológicas: para o desenvolvimento da actividade metodológica $n^{\circ} 5$, que servirá de encerramento das acções metodológicas para a preparação dos professores para o desenvolvimento da orientação profissional dos estudantes do primeiro ano do curso de Matemática, que tem como base a preparação prévia realizada por cada professor, onde os mesmos trarão por escrito às dúvidas e os aspectos fundamentais tratados nas actividades metodológicas anteriores.

Esta actividade metodológica deve ser desenvolvida por um professor com experiência ou com maior categoria. Recomenda-se que as temáticas do seminário sejam entregues com anterioridade aos participantes. 
O trabalho será novamente desenvolvido pelas equipas. Duas equipas trabalharão com os princípios e duas com os pilares básicos do processo de ensino.

Princípio fundamentais para transmitir esse interesse em álgebra, lógica ou resolução de problemas. Segundo Mayer (1981, p.135):

1. Promover a intuição, o diálogo, favorecendo a conversa entre o professor e os estudantes, bem como aos estudantes entre si de modo que sejam os próprios estudantes a encontrar as respostas e não o professor que as facilita.

2. Esse aprendizado direcciona a avaliação e não vice-versa. Avaliar habilidades ao invés um plano de estudos, entendendo a avaliação não como um exame, mas como um processo personalizado no qual os estudantes podem aprender e trabalhar, tanto o que aprenderam como o que precisam melhorar.

3. Incorporar novas tecnologias na formulação de problemas, tornando-as atraentes, para que os problemas teóricos se tornem situações reais que devem ser resolvidas. Isso dá-nos uma lição sobre a diferença entre comunicar (transmitir alguns conceitos) e conectar (estabelecer um link) que vemos neste exemplo.

Pilares sobre os quais o processo de aprendizagem de Matemática é construído no estudante, propostos por Bravo (2014, p.37):

1. Emoção: refere-se a querer fazer. A primeira fase para resolver um problema é querer resolvê-lo.

2. Criatividade: Você tem que gerar ideias. Devemos admitir todas as ideias por mais absurdas que possam parecer, mas sempre com filtros orientados pelo professor para consciencializar de seus erros, para o qual é necessário começar a partir do nível de compreensão (ideias e vocabulários) dos estudantes.

3. Raciocínio: é intrínseco à pessoa, e o processo de aprendizagem precisa ser mais desenvolvido.

4. Cálculo. É a parte qualitativa do processo, o resultado final.

5. É por isso que a pessoa que ensina, deve-se preocupar-se em dominar a sua matéria e ouvir o estudante, devendo também ser colocada no contexto dos estudantes para que o aprendizado seja mais relevante e, portanto, mais relacionado ao seu quotidiano. 
Avaliação: após o término do debate, o professor que dirige a actividade, pede a todos que leiam a seguinte expressão e avaliem como as acções metodológicas desenvolvidas, contribuíram para o processo de superação da orientação profissional:

"Capacidade de assumir novos requisitos curriculares, metodológicos e tecnológicos; capacidade de planificar acções didácticas em Matemática; capacidade de usar várias estratégias de ensino; capacidade de entender, identificar e aplicar teorias de aprendizagem em Matemática"

\section{CONCLUSÕES}

A sistematização dos referentes teóricos e metodológicos consultados e usados nesta investigação permitiram revelar que a orientação profissional, na actualidade, é concebida como um processo dinâmico e contínuo que começa desde a tenra idade, continua com o ingresso do aluno num centro de formação profissional e se reafirma durante a formação no curso que estuda e no exercício deste, uma vez que esteja a exercê-lo.

A aplicação de métodos e instrumentos utilizados durante a colheita de dados, o diagnóstico permitiu determinar que a preparação dos professores para o trabalho de orientação profissional dos estudantes do primeiro ano do curso de Matemática regular do ISCED-Huambo é débil, pouco metódico, espontâneo, o que dificulta a realização eficiente do processo de orientação profissional dos estudantes.

A proposta de acções metodológicas, previamente elaborados pode constituir via fundamental para a preparação dos professores no trabalho de orientação profissional dos estudantes do primeiro ano do curso de Matemática regular do ISCED-Huambo, pois se apresentam de forma dinâmica, motivadora e, sobretudo desenvolvedora.

\section{REFERÊNCIAS BIBLIOGRÁFICAS}

Alves, M. (2012). Metodologia Científica. Lisboa: Escolar Editora.

Bello, J. (2005). Metodologia Científica: Manual para elaboração de textos

Cueli, J. (1973). Vocación y afectos. México: Editorial Limusa. Walley. S.A.

Chipindo, P. C. M. (2020). A preparação dos professores para o trabalho metodológico de orientação profissional dos alunos do Instituto Técnico Agrário do Huambo. RAC: Revista Angolana De Ciências, 2 (1), 06-31.

Eco, U. (2007). Como se faz uma Tese em Ciências Humanas. 13 ed. Lisboa: Editora Presença. 
Educação, M. (2016). Lei de Base do Sistema de Educação de Angola 17/2016. República de Angola: Luanda.

Finerman, G. (1968). Psicotecnia y orientación profesional. Buenos Aires: Editorial El Ateneo.

González, V. (2003). La orientación profesional desde la Perspectiva HistoricoCultural del Desarrollo Humano. Habana: Revista Cubana de Psicologia.

Kapitiya, F. (2014). A,B,C. de Metodologia de Investigação Científica. Lobito: Secretariado Diocesano de Pastoral.

Parsons, F. \& Fingermann (1968). Choosing a vocation. Boston, MA: Houghton Mifflin.

Ramos, S., \& Naranjo, E. (2014). Metodologia de Invetigação Cientifica. Angola: Escolar Editora.

Savilombo, A. (2018). Potencialidades que a aula oferece para a orientação profissional. Revista Órbita Pedagógica. 5(3), 54-61.

Sierra, V., \& Zayas, C. (1998). Metodologia de la investigação Científica. Centro de Estudios de Educacion Superior "Manuel F. Gran". Universidade do Oriente. Cuba: Santiago de Cuba.

Soares, D. (1993). Pensando e Vivendo a Orientação Profissional. São Paulo Summs Editorial.

Super, D. E. (1968). The psychology of careers: An introdution to vocational development. New York.

Super, D., Ginzberg, C., \& Hará, A. (1978). Vocatinal development in adolescence and early adulthood: Tasks and behaviors . 